\title{
REVIEW
}

\section{Perspectives from the Society for Pediatric Research: interventions targeting social needs in pediatric clinical care}

\author{
Andrew F. Beck ${ }^{1,2}$, Alicia J. Cohen ${ }^{2,3}$, Jeffrey D. Colvin ${ }^{2,4}$, Caroline M. Fichtenberg ${ }^{2}$, Eric W. Fleegler ${ }^{2,5}$, Arvin Garg ${ }^{2,6}$, Laura M. Gottlieb ${ }^{2,7}$,
} Matthew S. Pantell ${ }^{2,8}$, Megan T. Sandel ${ }^{2,6}$, Adam Schickedanz ${ }^{2,9}$ and Robert S. Kahn ${ }^{1,2}$

\begin{abstract}
The social determinants of health (SDoH) are defined by the World Health Organization as the "conditions in which people are born, grow, live, work, and age." Within pediatrics, studies have highlighted links between these underlying social, economic, and environmental conditions, and a range of health outcomes related to both acute and chronic disease. Additionally, within the adult literature, multiple studies have shown significant links between social problems experienced during childhood and "adult diseases" such as diabetes mellitus and hypertension. A variety of potential mechanisms for such links have been explored including differential access to care, exposure to carcinogens and pathogens, health-affecting behaviors, and physiologic responses to allostatic load (i.e., toxic stress). This robust literature supports the importance of the SDoH and the development and evaluation of social needs interventions. These interventions are also driven by evolving economic realities, most importantly, the shift from fee-for-service to value-based payment models. This article reviews existing evidence regarding pediatric-focused clinical interventions that address the SDoH, those that target basic needs such as food insecurity, housing insecurity, and diminished access to care. The paper summarizes common challenges encountered in the evaluation of such interventions. Finally, the paper concludes by introducing key opportunities for future inquiry.
\end{abstract}

Pediatric Research (2018) 84:10-21; https://doi.org/10.1038/s41390-018-0012-1

The social determinants of health (SDoH) are defined by the World Health Organization as "the conditions in which people are born, grow, work, live, and age, and the wider set of forces and systems shaping the conditions of daily life." ${ }^{11}$ The SDoH frequently involves "upstream" social, environmental, and economic challenges related to housing or food insecurity, intimate partner violence, and a lack of clean air, alongside societal or structural determinants such as racism and poverty. ${ }^{2}$ Child poverty is a particularly prevalent determinant with more than $40 \%$ of children living in low-income households. ${ }^{3}$ Poverty and other related SDoH influence short- and long-term outcomes at the individual level, while differential exposures across groups generate disparities at the population level.

Neither does every individual has the same access to healthpromoting resources nor the same exposures to health-harming risks. This variability influences population health, "the health outcomes of a group of individuals, including the distribution of outcomes within that group." ${ }^{4}$ This distribution is inequitable when there is a "failure to avoid or overcome inequalities that infringe the fairness and human rights norms." ${ }^{5}$ Population health equity, therefore, requires consideration of all factors influencing both outcomes and outcome distributions. 6 , 7
An evolution toward value-based payments is pushing clinical providers, payers, hospitals, and health-care systems to develop and evaluate interventions that more effectively address such factors. Certain health-care organizations approach the SDoH through broad-based partnerships and programs aimed at improving housing stock, elevating economic opportunities, and reducing poverty in low-income communities. ${ }^{8}$ These approaches occur outside the clinical settings, but are complemented by clinically based patient-level interventions frequently involving screenings, case management, and assistance with services that reduce poverty-related hardships at the root of many SDoH.

In this paper, we begin with a brief description of mechanistic links between social determinants and health outcomes. We then highlight the evolving incentives that are accelerating the actions addressing the $\mathrm{SDoH} .{ }^{3,9-11}$ We then review the existing evidence generated about clinically based, patient-level pediatric interventions that focus on the basic needs. Finally, we outline common challenges researchers encounter in the evaluation of such interventions and offer several research opportunities critical to advancing the field in meaningful, value-added ways.

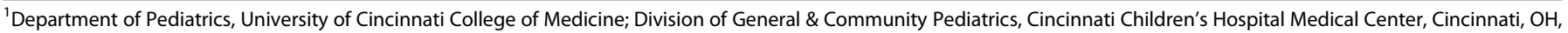

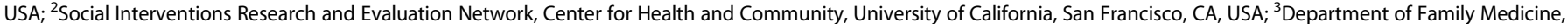

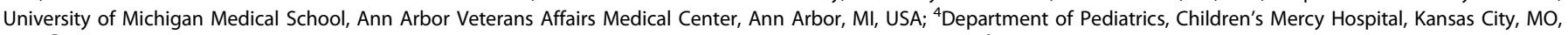

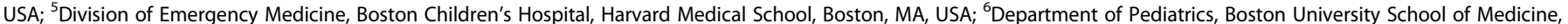

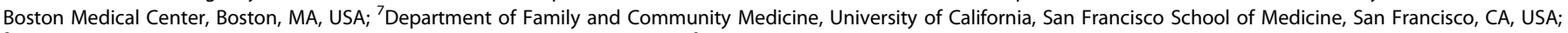

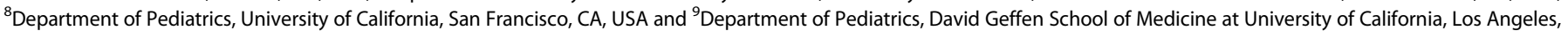
CA, USA

Correspondence: Andrew F. Beck (Andrew.Beck1@cchmc.org)
}

Received: 15 December 2017 Revised: 5 March 2018 Accepted: 10 March 2018

Published online: 23 May 2018 


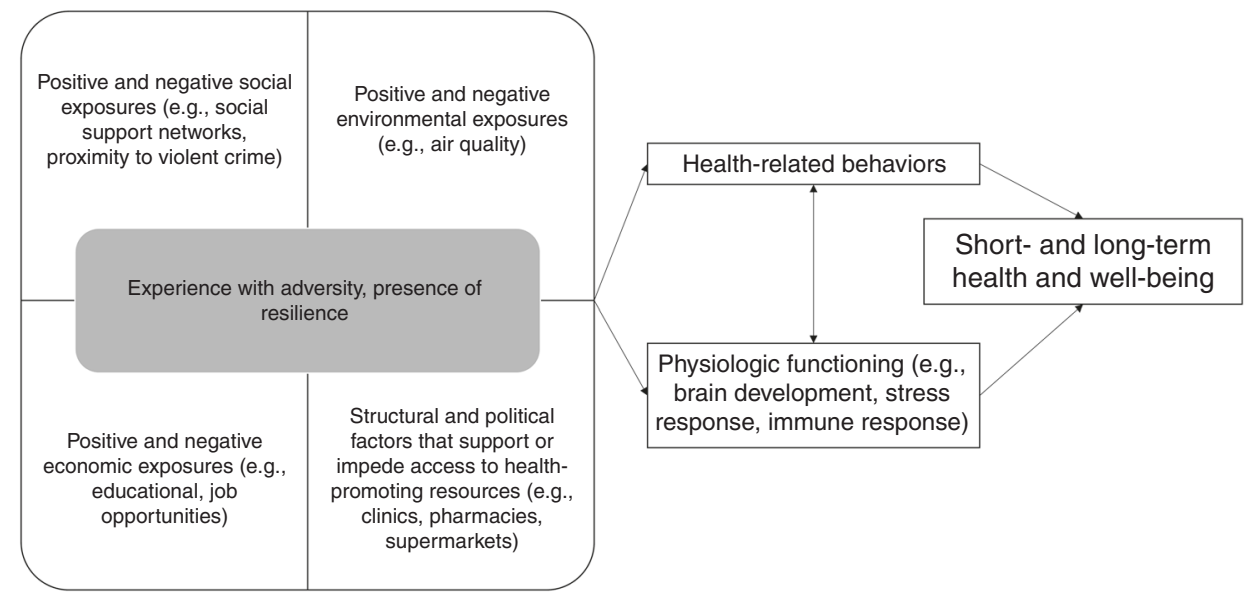

Fig. 1 Simplified conceptual framework linking exposures related to the social determinants to health outcomes across the life course

\section{MECHANISTIC LINKS BETWEEN SOCIAL DETERMINANTS AND HEALTH OUTCOMES}

Generally, people with social needs are at increased risk for morbidity and mortality. ${ }^{12}$ There are a variety of potential mechanisms for such links. ${ }^{13}$ Figure 1 provides a simplified conceptual framework for how SDoH-related conditions, exposures, and needs can be traced to health outcomes for individuals, households, and populations. Related, long-standing societal and structural determinants can also support or impede access to health-promoting resources. ${ }^{14}$ The influence of these factors, each often rooted in poverty, are interactive and cumulative, with exposures to multiple risks conferring a higher likelihood of poor health. ${ }^{13,15}$ For example, those exposed to polluted air are likely to also have limited access to affordable groceries and few opportunities for gainful employment. ${ }^{16-18}$

Those who navigate through daily hardships are less likely to adhere to medical regimens or preventive care. ${ }^{19}$ Moreover, the $\mathrm{SDoH}$ can "get under the skin." Socially disadvantaged children experience more insulin resistance, proinflammatory mRNA expression patterns, chronic cortisol elevation, and shorter telomere length (marker of premature aging and predictor of many diseases). ${ }^{20-23}$ Chronic or repetitive stress responses can become "toxic," altering immune functioning and neurodevelopment in ways that prompt more illness and delays in reaching the key milestones. ${ }^{24}$ This toxic stress is inextricably linked to lingering effects of adverse childhood experiences (ACEs) such as living with someone with mental illness or a substance use disorder, which themselves are linked to poorer adult health and premature death. $^{24-27}$

\section{INCENTIVIZING ACTION ON THE SOCIAL DETERMINANTS OF HEALTH}

We acknowledge that philanthropy, grants, and an institutional sense of "return on mission" are critical for the success of many SDoH-related interventions. That said, health-care payment models are evolving in ways that are changing the care practices, increasingly incentivizing quality and value. Nussbaum et al. recently outlined a framework through which alternative payment models can be considered. They highlight three themes amid such ongoing shifts: protecting patients against perverse economic incentives, protecting health-care professionals against undue risk, and developing value-based goals for the payment reform. ${ }^{11}$ Here, however, we primarily focus on the third of these themes, seeing the concept of "value-based goals" as accelerants for action on the $\mathrm{SDoH}$. We consider the current state of incentives, and we draw on the evidence, primarily from adults, for health-care-based actions on the SDoH.
Children with more social needs generally have higher rates of health-care utilization than their less at-risk peers including higher-hospitalization rates for ambulatory care sensitive conditions. ${ }^{28,} 29$ In fee-for-service models, increased utilization generally results in increased revenue. This may not be the case, however, for lower-income children covered by Medicaid. ${ }^{30,} 31$ Because Medicaid reimbursement is generally below that of Medicare and commercial insurers, many health-care institutions and providers equate more health service utilization with more unreimbursed costs. $^{32}$ As a result, health-care systems and hospitals, practices and providers, may see incentives to reduce potentially preventable utilization events. Still, the lack of reimbursement for $\mathrm{SDoH}$-focused interventions, and limited evidence for what works, has stood in the way of widespread adoption.

Yet, private insurers alongside the Centers for Medicare \& Medicaid Services (CMS) are advancing payment models, wherein providers and health-care systems are "at risk" for the costs for care or are rewarded for delivering high-value care. Unlike fee-forservice models, newer models such as accountable care organizations (ACO) allow greater flexibility in the use of payments from insurers ${ }^{33}$ including the freedom to use payments to address root causes of poor health-frequently, the SDoH. ${ }^{34}$ Presently, much of this work occurs among high-risk adults who are far more likely than children to add cost to the health-care system. For instance, Minnesota's Hennepin Health uses payments received through its ACO to integrate non-clinical, SDoH-relevant services into its health-care delivery system. Social workers, community health workers (CHW), social service navigators, and vocational counselors are now key contributors within Hennepin Health's primarycare clinics. Initial findings of decreased health-care utilization and costs, and increased preventive care visits are encouraging. ${ }^{35}$

Recent changes in Medicaid regulations also indicate that CMS is open to reimbursing providers who address the $\mathrm{SDoH} .{ }^{36,37}$ The Medicaid Health Homes program reimburses providers for the coordination of health-care services for individuals with chronic conditions including "referral to community and social support services." ${ }^{38}$ CMS also launched the Accountable Health Communities program, committing $\$ 157$ million to "assess whether systematically identifying and addressing health-related social needs can reduce health-care costs and utilization." ${ }^{39}$ Different tracks of this project will address identified needs through referrals to community resources or navigators. Finally, Vermont's Blueprint for Health, an all-payer model, now actively partners with community-based services. The program also assesses social needs as part of a focused root cause analysis for their patients with complex medical needs. ${ }^{40}$

As noted above, many of these innovations have involved highcost adults. The "cost" of social needs, and the "benefit" of 


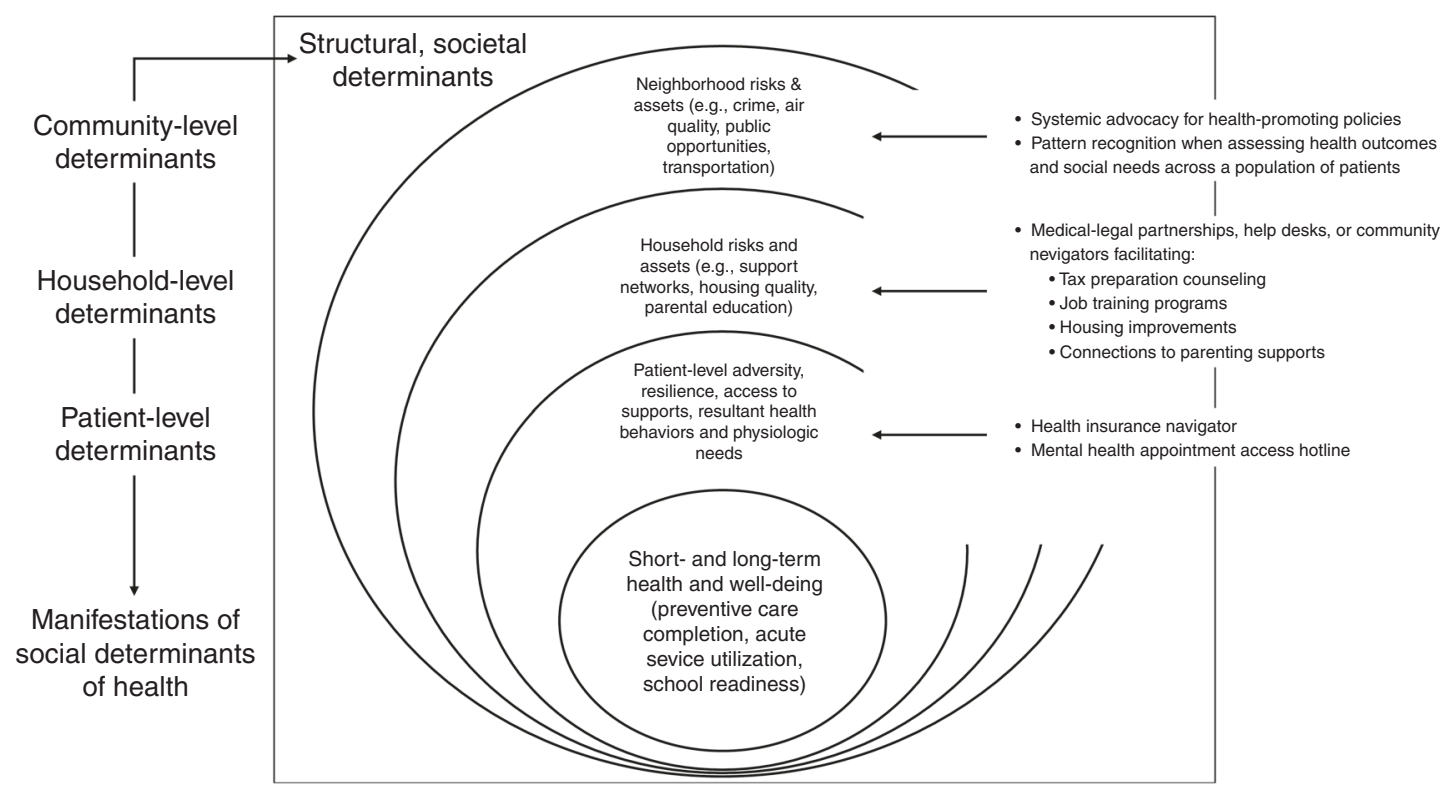

Fig. 2 Manifestations of potential social needs interventions to mitigate and address community-, household-, and patient-level social determinants of health

managing them effectively, likely needs to be thought of differently for children. Savings to the health-care sector in short term will probably be most robust when social needs are addressed among adults with chronic conditions, as in the examples cited above. Children, on the other hand, are relatively healthy, costing the health-care system relatively less, compared to adults with chronic conditions. That said, the possible impact of addressing social needs among children should not be discounted as it could improve both child health and the health of other members of the household. It could also yield longer-term cost reductions and benefits in health care and other non-health-care sectors (e.g., education, criminal justice, etc.) across an individual's lifespan. ${ }^{41-43}$ It may, therefore, behoove those tracking interventions including payers to consider outcomes beyond mere health service utilization. Thinking about rewarding broader societal outcomes such as school readiness, school attendance, or utilization of services across other sectors ${ }^{43}$ may be a step forward for health-care systems and for payers.

Although financial incentives may not always be the same for children and for adults, there is still a general push toward outcomes-oriented value-based care provision in pediatrics. Thus, pediatrics continue to grapple with how to develop and deploy value-added social needs interventions, particularly when the evidence on how to do so is limited. ${ }^{3,9}{ }^{44}$ We present Fig. 2 to illustrate the range of potential interventions across multiple, inter-related levels (e.g., patient, household, and community). We show how interventions at each level can map to the identified needs and then to resources or actions. Below, we focus on existing evidence for those interventions mapped to the patient and household levels and delivered in pediatric clinical settings, or in concert with those settings. We focus on both interventions that address multiple needs within one encounter and on those that target one specific health condition or a social need.

\section{EVIDENCE FOR SOCIAL NEEDS INTERVENTIONS}

To appraise the existing evidence on social needs interventions in pediatric settings, we updated and expanded upon a recent systematic review. ${ }^{45}$ The earlier review included peer-reviewed articles evaluating interventions published between January 2000 and February 2017. For this pediatric-targeted synthesis, we updated the prior review by searching PubMed and the Social
Interventions Research \& Evaluation Network (SIREN) Evidence Library, ${ }^{46}$ an online database of social interventions research, for additional evaluations of social needs interventions in pediatric settings published between February 2017 and September 2017. This search did not yield any additional studies. We abstracted the full results for the 13 total pediatric-targeted studies that we classified as being of moderate or high quality (based on GRADE quality rating). ${ }^{47}$ Studies fell into two broad categories: interventions screening and providing assistance with multiple social needs in the same encounter, and interventions targeting a specific health condition or a social need.

Three interventions addressed multiple needs in the same encounter: WE CARE, a primary-care-based program that uses a self-administered, paper-based screening tool, followed by a written referral sheet to resources addressing the identified needs; ${ }^{48,} 49$ DULCE, a program in which specialists work with families of infants to identify social needs and connect them with the available resources; ${ }^{50}$ and a volunteer-led, in-person social needs screening and navigation program deployed in primary and urgent care settings (Table 1). ${ }^{51}$ Studies of these programs reported beneficial effects on social and health outcomes. Compared to controls, WE CARE parents were more likely to receive $\geq 1$ social referral and enroll in $\geq 1$ new resource (e.g., maternal employment and childcare programs); they were also found to be less likely to live in homeless shelters. ${ }^{48,49}$ DULCE was associated with significantly increased access to supports addressing food, benefits, and utilities; increased receipt of routine immunizations and preventive care visits; and decreased emergency department (ED) visits by the age of 6 months. ${ }^{50}$ Finally, the volunteer-led navigation program was associated with decreased social needs and improved caregiver-reported child health, compared with provision of written resources alone (active control), as measured at 4 months. ${ }^{51}$

Interventions targeting either a specific condition or specific social need were: three looking at CHW-driven, home-based asthma education, and trigger reduction programs; two focusing on child development interventions; and four evaluating the Safe Environment for Every Kid (SEEK) resident training program designed to prevent child maltreatment (Table 2). The homebased asthma programs reported mixed results across a range of outcomes. Krieger et al. found improvements in caregiverreported quality-of-life scores and reductions in asthma-related 


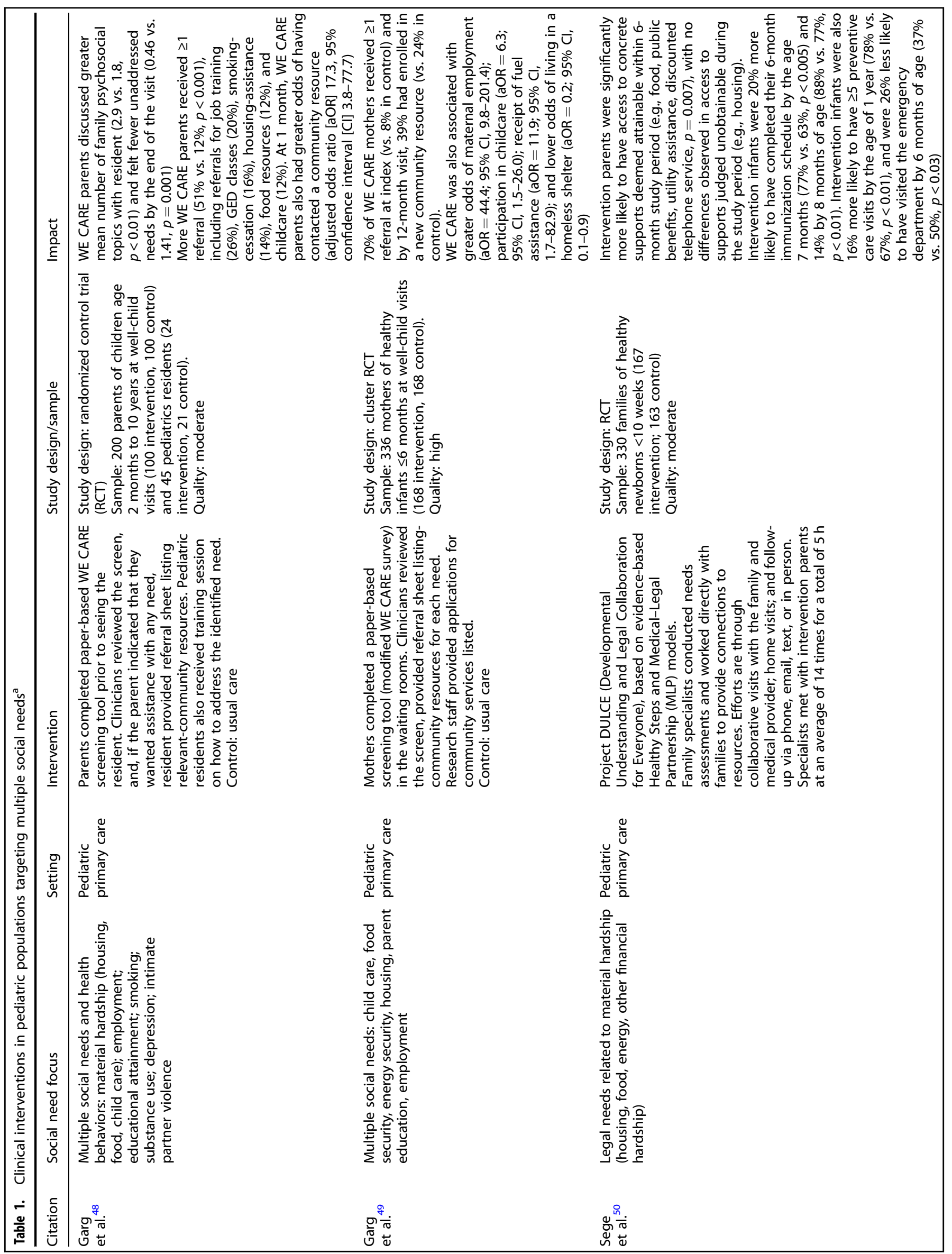


acute utilization; they found no decline in asthma symptom days. $^{52}$ In contrast, Campbell et al. found that a streamlined version of Krieger et al.'s intervention decreased the number of asthma symptom days, improved caregiver-reported quality-oflife, and reduced acute utilization. ${ }^{53}$ Finally, a separate intervention pursued by Williams et al. led to measurable reductions in dust-mite allergen levels and improvements in asthma-related functional severity scores. However, they noted no significant effect on the medication use, ED visits, or hospitalizations. ${ }^{54}$

Among the two studies focused on child development, Silverstein et al. found that primary case-based outreach to Head Start sites on behalf of families nearly doubled the successful connections (defined as either actively attending or being placed on Head Start waiting list). ${ }^{55}$ Similarly, Mendelsohn et al. examined the impact of two primary-care-based parent-child interaction interventions built on the Reach Out and Read model, one delivered by a child development specialist and the other through written materials mailed monthly to the home. Both programs were associated with increases in parent-child interaction at 6 months, although, the in-person program had larger effects. ${ }^{56}$

Finally, four studies evaluated SEEK. ${ }^{57-60}$ SEEK trains providers to screen for and help connect families with services to address six risk factors for child maltreatment: maternal depression, substance use, intimate partner violence, harsh punishment, parental stress, and food insecurity. SEEK led to reductions in child maltreatment in high- and low-risk settings-fewer instances of severe physical assaults and medical neglect, fewer families with $\geq 1$ child protective services report, and fewer with delayed immunizations. They also reported less psychological aggression and minor assaults at both the initial and 12-month follow-up visits. ${ }^{57}$ Provider-perceived competence and comfort also improved in four of the six risk areas. ${ }^{60}$

Despite an expectation that social needs interventions in health care settings could improve child health, this review identified only three high-quality studies (ten of moderate quality). The small number and heterogeneous nature of these studies make it difficult to draw broad conclusions, but several patterns did emerge. Most interventions relied upon trained specialists for the evaluation and treatment of identified social needs; they also had the potential for multiple visits or telephone follow-ups. That said, the two "singletouch" interventions both involved training pediatric residents to identify unmet needs and provided either a printed referral listed (WE CARE) or referral to a social worker or mental health professional (SEEK). Future research is needed to determine the relative merits of interventions that rely on screening and evaluation by a trained specialist (e.g., social worker), compared to relying on the patient-provider encounter. Also, although interventions involving multiple visits can be resource intensive, Gottlieb et al. found that inperson navigation with telephone follow-up was superior to a onetime provision of printed resources. ${ }^{51}$ Similarly, the higher intensity home-based asthma intervention involving multiple $\mathrm{CHW}$ visits resulted in greater projected 4-year net cost savings than the lower intensity intervention involving just one visit. ${ }^{52}$

Our synthesis did include 22 additional studies evaluating pediatric social needs interventions in health-care settings that were of lower quality, based on sample size or study design. ${ }^{61-82}$ Some have addressed areas that have been gaps in the pediatric SDoH literature including interventions focused on: (1) specific populations like young adults; ${ }^{77-80,82}$ (2) settings such as EDs and trauma centers; ${ }^{77-79,} 82$ (3) different modes of screening (e.g., paper and online); ${ }^{80}$ and (4) models like Health Leads and medical-legal partnerships. ${ }^{69,} 70,72-76$ Others relied on quality improvement methods supportive of real-world implementation, sacrificing internal for external validity. ${ }^{62}$ While many yielded promising findings, more research is needed to confirm their reproducibility and generalizability. The next sections will expand upon these and other challenges facing the field, as well as the many opportunities for future evidence generation. 


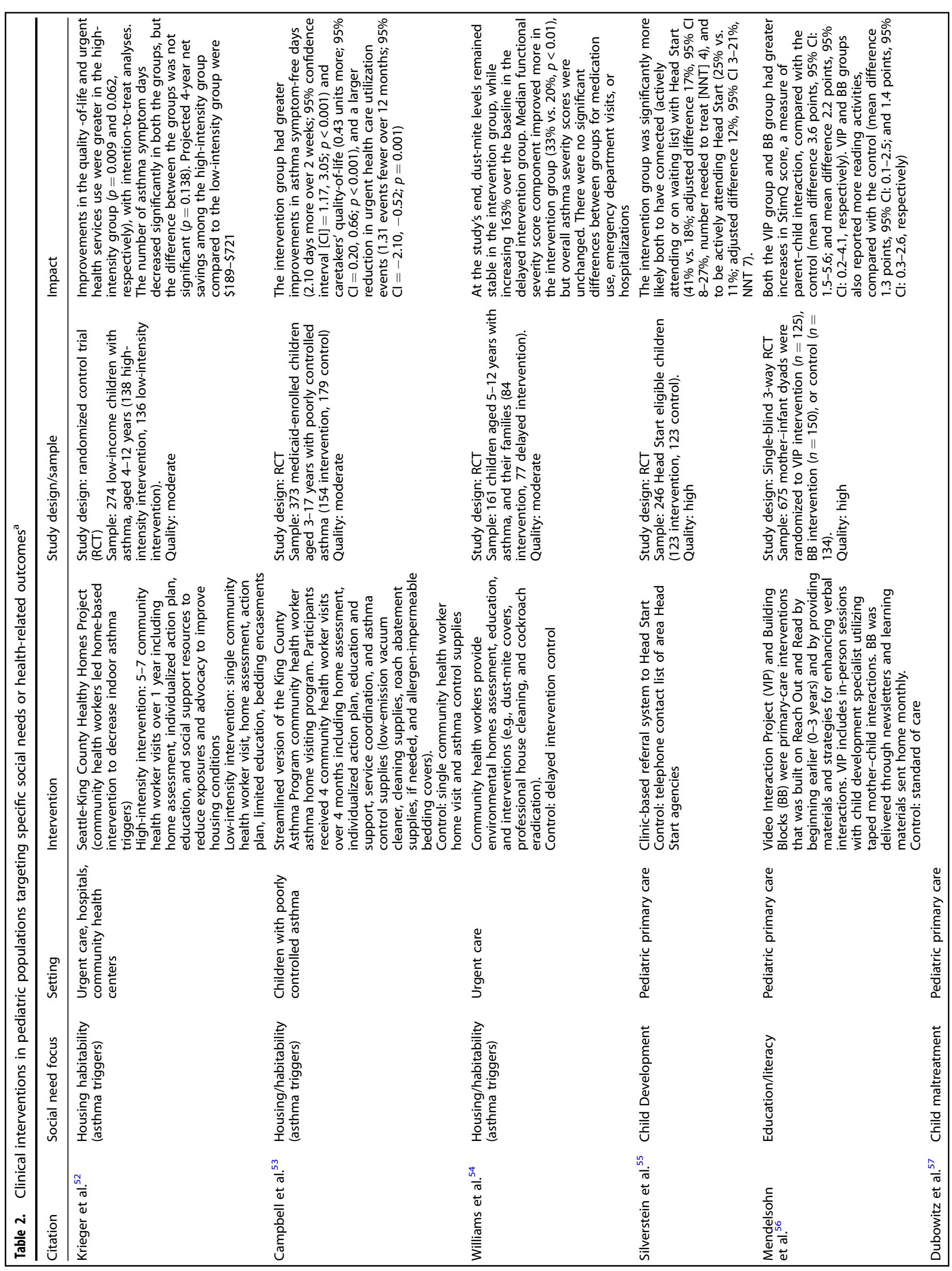




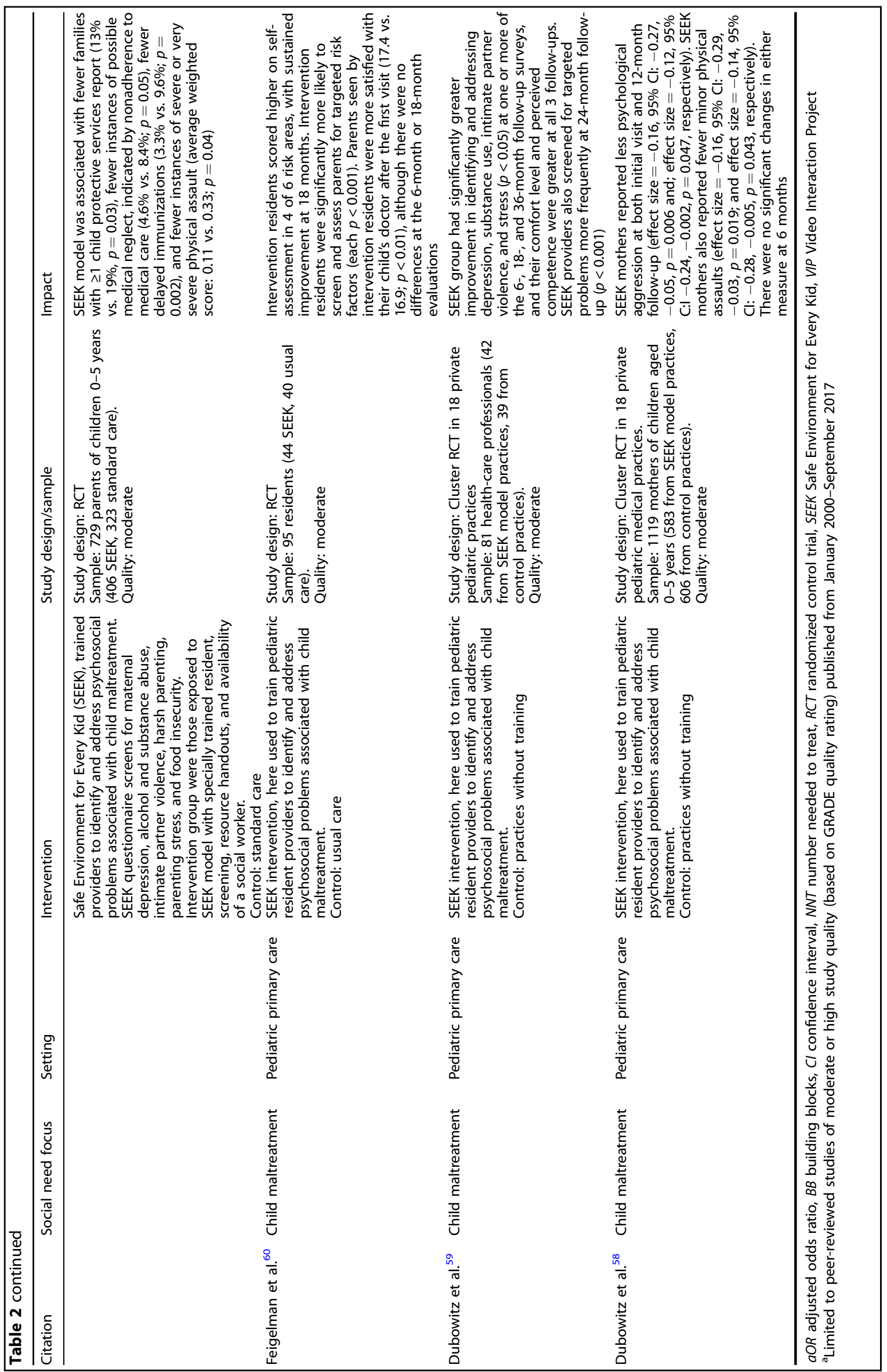




\begin{tabular}{|c|c|}
\hline Category & Challenges or considerations to take into account \\
\hline \multirow[t]{6}{*}{ Conceptual } & Local nature of intervention and treatment effect \\
\hline & Difficulty in determining "dose" of intervention \\
\hline & Questions related to equipoise, is it ethical to randomize? \\
\hline & $\begin{array}{l}\text { Outcome determination, given the multifactorial nature } \\
\text { of how social determinants affect health }\end{array}$ \\
\hline & One social risk rarely felt in isolation \\
\hline & Social risks and needs can recur \\
\hline \multirow[t]{5}{*}{ Design } & $\begin{array}{l}\text { Treatment may be outside the purview of the clinical } \\
\text { setting }\end{array}$ \\
\hline & Potential for selection bias \\
\hline & $\begin{array}{l}\text { Potential for contamination, spillover, treatment group } \\
\text { crossover }\end{array}$ \\
\hline & $\begin{array}{l}\text { Ambiguity around how intervention can be } \\
\text { operationalized and defined }\end{array}$ \\
\hline & Questions around hypothesized time to effect \\
\hline \multirow[t]{3}{*}{ Analytic } & $\begin{array}{l}\text { Questions related to what constitutes completion of } \\
\text { intervention }\end{array}$ \\
\hline & $\begin{array}{l}\text { Heterogeneity in what constitutes social need being } \\
\text { addressed }\end{array}$ \\
\hline & Attrition, the potential threats to follow-up \\
\hline
\end{tabular}

\section{CHALLENGES RELATED TO RESEARCH ON SOCIAL NEEDS INTERVENTIONS}

Research on social needs interventions has similar challenges to those found in traditional clinical, health services, and social science research. Still, certain unique challenges warrant explicit consideration (Table 3). First, the "treatment" for a social need is often outside the purview of clinical medicine (even if deployed in a clinical setting). Interventions frequently rely upon referral or connection to a fragmented, underfunded, fragile safety net of community-based organizations and agencies, potentially complicating how interventions are experienced. Second, nonrandomized studies may be limited by selection bias and reverse causality when patients who are healthier are also more capable of improving their social circumstances. Third, partnerships, resources, and services can be variable in terms of accessibility and effectiveness both within and across communities; this makes it hard to generalize the findings from one setting to another. Fourth, interventions cannot be dosed with pharmaceutical precision. An intervention's effectiveness depends on many hard-to-measure factors such as trust and patient engagement. These and other conceptual, design, and analytic challenges are worthy of consideration, as we seek strategies capable of advancing the field.

\section{Conceptual considerations}

Social needs interventions have known social benefits, even if their health benefits are still being described. One may ask whether it is appropriate to randomize and, if so, what represents an ethical control group. We must also carefully consider what measures are most pertinent to our intervention or our question. At one level, researchers may focus on whether the intervention (e.g., referral to community resource) is worth the clinical time and resources it may take. How does it affect the clinic flow or patient satisfaction? What are the most pertinent health outcomes to measure? To answer these questions, researchers must grapple with the reality that social needs may influence health directly (i.e., through malnutrition in food insecurity) and indirectly (i.e., through forced choices between food and needed medical care).
They may also influence other outcomes such as school readiness or third-grade reading ability that are not always seen as "health" outcomes. Interventions may also address social symptoms and not root causes (e.g., multigenerational poverty, historical and current discrimination). Such "symptoms" often cluster with one another and can recur, especially when their root cause lingers, potentially necessitating sustained intervention in order to see the sustained effect.

\section{Design considerations}

Other barriers make the achievement of gold standard evidence generation difficult for social needs interventions. While randomization may be possible, blinding often is not. Moreover, intervention uptake can be patient-dependent; contamination, spillover, and treatment group crossover is likely. Therefore, randomized trials likely cannot meet the evidentiary ideal and, if attempted, it must account for these challenges, such as through cluster randomization. Quasi-experimental study designs (e.g., stepped-wedge) may provide practical alternatives to randomized trials.

There are also unanswered questions and ambiguity surrounding the choices of who, what, where, when, and how to screen, refer, and follow up. Social needs interventions are highly customizable, making it difficult to know which design choices affect outcomes and which are trivial. For example, frequently used screening tools were generally not designed to measure patientdefined needs or patients' desire for assistance. Thus, "validated" screens may not accurately capture those needs that patients care about the most. ${ }^{80,83}$ Although addressing social needs should be patient-centered and involve shared decision-making, few current interventions have been designed within this framework. Finally, any clinic-based screening can have inherent limitations; falsepositive and false-negative responses may have unintended consequences on the provider-patient relationship. ${ }^{84,} 85$

Time to effect is another critical issue. Factors addressed by interventions may improve health in both the short and long term, but it is not clear when the health impact will be the greatest. How long should patients be followed to observe an effect? What study duration is practical in populations with high rates of housing instability and changing phone numbers? How do we account for the cyclical nature of many social problems?

All this complexity means that a priori study plans should pay close attention to procedures around screening, setting, workforce, and time to follow-up. That said, real-world effectiveness is of similar import, with studies needed that are both internally and externally valid. There is an abundance of evidence illustrating that efficacy trial findings are often not replicable in real-world settings. Thus, we propose that hybrid effectivenessimplementation designs, pragmatic trials, and/or quality improvement studies are needed to accelerate intervention evaluation and adoption. For interventions driven by partnered organizations, design decisions must account for common partner-related challenges (e.g., capacity, reach, and measurement capability).

\section{Analytic considerations}

The intervention threshold at which an impact on outcomes occurs may not be intuitive. For instance, a patient screened and referred to an intervention may only experience the expected outcome if they follow through and visit the social needs resource. Should just those patients completing all process stages-screen, referral, and follow-up-be treated as receiving the full intervention? What threshold of service engagement defines intervention delivery-initial follow through with the service or some action arising from the intervention (e.g., going to a social service agency, applying for a benefit, or receiving the benefit)? Intention-to-treat analyses with secondary examinations of successfully connected patient subgroups provide a prudent, but difficult-to-analyze, approach that walks this balance in intervention trials. ${ }^{86}$ 
Table 4. Opportunities for researchers studying social needs interventions to move the field forward

\begin{tabular}{ll}
\hline Category & Opportunities for further inquiry \\
\hline Measurement & Identifying and defining process and outcome measures \\
& Determination of differential intervention effects on certain patients, populations, or geographies \\
& Consideration of how social needs may link to biomarkers, health-care utilization, and costs \\
Intervention & Benchmarking cost-effectiveness of interventions against medical treatments/interventions \\
& Assessing different means through which screening occurs \\
& Identifying best practices for referrals to relevant resources \\
& Identifying best practices for community-partnership building, intervention codesign \\
& Patient or family view of social needs interventions in clinical settings \\
Methodologic & Comparative effectiveness of existing interventions and different intervention strategies \\
& Relationship to advocacy for social safety net programs \\
& Alternative epidemiologic study designs \\
& Use of implementation science, quality improvement methods
\end{tabular}

There is additional intervention heterogeneity with respect to which specific social needs are addressed. Should the impact on patients connected to housing supports versus food pantries be analyzed as though they received the same or different interventions if they both arose from the same screening and referral processes? One analytic approach could examine all screened patients combined, regardless of need category, followed by an examination of subgroups to understand differential effects by category. Propensity score matching, inverse probability weighting, and instrumental variables may be other strategies that can help social needs researchers increase the validity of their inferences. ${ }^{87}$

\section{OPPORTUNITIES FOR FURTHER RESEARCH}

Research challenges are surmountable and often represent opportunities for innovation and groundbreaking investigation. There remain plenty of ways to advance the work and address fundamental questions about how health care delivery systems can evolve to better meet the needs of patients and families. In the section below, we provide a comprehensive outline of potential opportunities for further research. A summarized, prioritized list of such opportunities is also shared in Table 4.

There is substantial heterogeneity across SDoH-relevant metrics. $^{37,} 45$ Many studies focus on proximal process measures, including intervention feasibility, connections to resources, and specific improvements in unmet social needs. Few of them examine the impact of interventions on health outcomes or outcomes critical to child wellness (e.g., school readiness). Researchers could assess how interventions affect measures, which, themselves, have known linkages to morbidity and mortality. Indeed, this is where identifying intermediary outcomes linked to downstream cost and utilization could be a useful strategy. For example, interventions targeting food insecurity could measure successful enrollment of eligible patients and families into the Supplemental Nutrition Assistance Program (SNAP). Then, the known positive outcomes that result from SNAP enrollment could be tied back to the intervention, highlighting the known effects SNAP receipt has on lower health-care expenditures, improved food insecurity, and more money to spend on other basic needs. ${ }^{88,} 89$

We also suggest that research should explore whether interventions have differential effects based on underlying patient- or population-level social, medical, or demographic risk profiles. Not every patient (or population) should be expected to benefit equally from every intervention. Similarly, those from one neighborhood, or region, may experience needs and interventions differently from those living elsewhere. Certain conditions, too, may be more amenable to improvements from social needs interventions than others: asthma has long been linked to housing conditions, nutritional deficiencies to food insecurity. Established and other hypothesized mechanistic links could be valuable guides as researchers seek more condition-specific outcomes (e.g., pulmonary function tests for asthma) or biomarkers (e.g., HgbA1C for diabetes) to measure as their interventions are implemented. Research illuminating how medical and social factors intersect and interact would similarly push us forward.

Clearly, there is considerable interest related to how social needs interventions affect health-care costs and utilization for specific conditions and across all conditions. An impact on costs or utilization could justify new funding streams for such interventions. While studies assessing utilization (and their costs) are needed, a positive return on investment is a high bar that almost no other medical intervention is held to, let alone interventions that have positive social and economic merits irrespective of their medical consequences. ${ }^{43}$ Therefore, researchers might consider benchmarking the cost-effectiveness of their interventions against common, well-accepted medical treatments when making the case for inclusion of social needs interventions in the clinical armamentarium. Researchers should also be prepared for the possibility that social needs interventions may actually increase utilization and costs in some settings, at least in the short term, particularly if interventions are valued by patients and supports are difficult to access elsewhere.

Perhaps, the most immediate research priorities have to do is with understanding the best screening tools, referral pathways, and intervention-implementation logistics. Much attention has been placed on selecting and validating screening items and methods for social needs in clinical settings. ${ }^{90-94}$ The steps of community-partnership building, resource referral, follow-up, and feedback loops back to the health-care delivery system are more opaque. ${ }^{95}$ Research opportunities abound across the continuum of care, from understanding providers' receptivity to hearing about social needs and patient/family acceptability of screening to ensuring that patients consistently receive the right resource at the right time. ${ }^{59,60,83,96,97}$ Further research is also needed to better understand the nuances of screening for "symptoms" of need versus patients' desire for assistance, and how health-care systems can best navigate both the need for data gathering and provision of that which is of most value to patients. ${ }^{83}$ Of course, the effectiveness of every element of this continuum is contingent upon the strength of other links in the screening and referral chain (e.g., capacity and capability of the partnering agency), but very little research to date has provided even a basic understanding of this process from start to finish. This area of research would lend itself to tools such as patient journey mapping and qualitative 
methods to define patient experiences and expectations of such programs. Resource scans and directed advocacy, regional and national, may also be relevant, particularly as aspects of the social safety net find themselves up for debate in policy circles. ${ }^{98}$

Comparative effectiveness research provides a useful framework for considering different intervention models. Key, yet-to-beaddressed questions, cut to the heart of the justification for clinical social needs interventions, such as whether co-location of services (i.e., medical-legal partnerships, medical-financial partnerships, and on-site food pantries) are more effective at moving outcomes than linkages to community-based services (i.e., help desks that refer patients out for resources). ${ }^{49,} 62,70,74$ Questions of the best workforce (physician, social worker, $\mathrm{CHW}$, and volunteer advocate) remain unaddressed. There is also limited evidence regarding the most effective or efficient settings (inpatient, outpatient, and ED) ${ }^{99}$ and the medium (paper, tablet, and electronic patient portal) ${ }^{92}$ for screening. Other critical process and implementation questionssuch as what populations to target, how often to screen, what frequency of follow-up, and how best to document and communicate social needs in the health record are similarly important and underexplored. Finally, across every level of the health-care delivery system, the field has yet-to-define factors that make success of social needs interventions more probable, sustainable, and scalable. Such advances are critical given the goal of meeting the breadth of existing need. Relatedly, we

must collectively define how to promote the needed collaboration and trust between medical and social systems, and with patients and families, that have traditionally been bureaucratic and siloed.

Given the expanding relevance and interest in SDoH-related research, we propose that networked, aligned researchers have the best chance at answering these numerous, challenging questions. With input from a diverse group of research-thought leaders from around the United States and Canada, and support from Kaiser Permanente, the Robert Wood Johnson Foundation, and the Commonwealth Fund, SIREN was created in 2016 to help synthesize, catalyze, and disseminate high-quality research focused on health-care-based social needs interventions, helping support-shared learning across this growing field. ${ }^{100}$

\section{CONCLUSIONS}

A wealth of evidence now supports the influence the social determinants have on health outcomes. Increasingly, incentives are pulling us toward the development and deployment of interventions targeting social needs. While research challenges exist, there are tremendous opportunities to determine how to best address those basic needs known to have such a critical impact on health across the life course.

\section{ADDITIONAL INFORMATION}

Competing interests: The authors declare that they have no competing interests.

Publisher's note: Springer Nature remains neutral with regard to jurisdictional claims in published maps and institutional affiliations.

\section{REFERENCES}

1. World Health Organization. Social Determinants of Health http://www.who.int/ social_determinants/en/ (2017). Accessed 25 May 2017.

2. Braveman, P., Egerter, S. \& Williams, D. R. The social determinants of health: coming of age. Annu. Rev. Public Health 32, 381-398 (2011).

3. Council on Community Pediatrics. Poverty and child health in the United States. Pediatrics 137, e20160339 (2016).

4. Kindig, D. \& Stoddart, G. What is population health? Am. J. Public Health 93, 380-383 (2003).

5. World Health Organization. Health Systems: Equity http://www.who.int/ healthsystems/topics/equity/en/ (2017). Accessed 29 Jan 2017.
6. Sharfstein, J. M. The strange journey of population health. Milbank $Q$ 92, 640-643 (2014).

7. Woolf, S. H. Progress in achieving health equity requires attention to root causes. Health Aff. 36, 984-991 (2017).

8. Sandel, M. \& Desmond, M. Investing in housing for health improves both mission and margin. JAMA 318, 2291-2292 (2017).

9. Dreyer, B., Chung, P. J., Szilagyi, P. \& Wong, S. Child poverty in the United States today: introduction and executive summary. Acad. Pediatr. 16, S1-S5 (2016).

10. Dzau, V. J. et al. Vital directions for health and health care: priorities from a national academy of medicine initiative. JAMA 317, 1461-1470 (2017).

11. Nussbaum, S., McClellan, M. \& Metlay, G. Principles for a framework for alternative payment models. JAMA 319, 653-654 (2018).

12. The John D. and Catherine T. MacArthur Foundation Research Network on Socioeconomic Status and Health. Reaching for a Healthier Life: Facts on Socioeconomic Status and Health in the U.S. http://www.macses.ucsf.edu/News/ Reaching\%20for\%20a\%20Healthier\%20Life.pdf (2007). Accessed 3 Nov 2017.

13. Adler, N. E. \& Stewart, J. Health disparities across the lifespan: meaning, methods, and mechanisms. Ann. N. Y Acad. Sci. 1186, 5-23 (2010).

14. Dodge, K. A., Pettit, G. S. \& Bates, J. E. Socialization mediators of the relation between socioeconomic status and child conduct problems. Child Dev. 65 649-665 (1994).

15. Larson, K., Russ, S. A., Crall, J. J. \& Halfon, N. Influence of multiple social risks on children's health. Pediatrics 121, 337-344 (2008).

16. Dowd, J. B., Zajacova, A. \& Aiello, A. Early origins of health disparities: burden of infection, health, and socioeconomic status in U.S. children. Soc. Sci. Med. 68, 699-707 (2009).

17. Walker, R. E., Keane, C. R. \& Burke, J. G. Disparities and access to healthy food in the United States: a review of food deserts literature. Health Place 16, 876-884 (2010).

18. Stevens, G. D., Seid, M., Pickering, T. A. \& Tsai, K. Y. National disparities in the quality of a medical home for children. Matern. Child Health J. 14, 580-589 (2010).

19. Smith, L. A. et al. Modifiable risk factors for suboptimal control and controller medication underuse among children with asthma. Pediatrics 122, 760-769 (2008).

20. Goodman, E., Daniels, S. R. \& Dolan, L. M. Socioeconomic disparities in insulin resistance: results from the Princeton School District Study. Psychosom. Med. 69, 61-67 (2007).

21. Needham, B. L., Fernandez, J. R., Lin, J., Epel, E. S. \& Blackburn, E. H. Socioeconomic status and cell aging in children. Soc. Sci. Med. 74, 1948-1951 (2012).

22. Miller, G. \& Chen, E. Unfavorable socioeconomic conditions in early life presage expression of proinflammatory phenotype in adolescence. Psychosom. Med. 69, 402-409 (2007)

23. Vliegenthart, J. et al. Socioeconomic status in children is associated with hair cortisol levels as a biological measure of chronic stress. Psychoneuroendocrinology 65, 9-14 (2016).

24. Shonkoff, J. P. et al. The lifelong effects of early childhood adversity and toxic stress. Pediatrics 129, e232-e246 (2012).

25. Felitti, V. J. et al. Relationship of childhood abuse and household dysfunction to many of the leading causes of death in adults. The Adverse Childhood Experiences (ACE) Study. Am. J. Prev. Med. 14, 245-258 (1998).

26. Brown, D. W. et al. Adverse childhood experiences and the risk of premature mortality. Am. J. Prev. Med. 37, 389-396 (2009).

27. Cohen, S., Janicki-Deverts, D., Chen, E. \& Matthews, K. A. Childhood socioeconomic status and adult health. Ann. N. Y. Acad. Sci. 1186, 37-55 (2010).

28. Lu, S. \& Kuo, D. Z. Hospital charges of potentially preventable pediatric hospitalizations. Acad. Pediatr. 12, 436-444 (2012).

29. Flores, G., Abreu, M., Tomany-Korman, S. \& Meurer, J. Keeping children with asthma out of hospitals: parents' and physicians' perspectives on how pediatric asthma hospitalizations can be prevented. Pediatrics 116, 957-965 (2005).

30. Health Insurance Coverage of Children 0-18 https://www.kff.org/other/stateindicator/children-0-18/?currentTimeframe=0\&sortModel=\%7B\%22colld\%22:\% 22Location\%22,\%22sort\%22:\%22asc\%22\%7D (2016). Accessed 17 Oct 2017.

31. Children's Health Coverage: The Role of Medicaid and CHIP and Issues for the Future https://www.kff.org/report-section/childrens-health-coverage-the-role-ofmedicaid-and-chip-and-issues-for-the-future-issue-brief/ (2016). Accessed 22 April 2017.

32. Colvin, J. D. et al. Financial loss for inpatient care of medicaid-insured children. JAMA Pediatr. 170, 1055-1062 (2016).

33. Eggleston, E. M. \& Finkelstein, J. A. Finding the role of health care in population health. JAMA 311, 797-798 (2014).

34. Fraze, T., Lewis, V. A., Rodriguez, H. P. \& Fisher, E. S. Housing, transportation, and food: how ACOs seek to improve population health by addressing nonmedical needs of patients. Health Aff. 35, 2109-2115 (2016).

35. Sandberg, S. F. et al. Hennepin health: a safety-net accountable care organization for the expanded Medicaid population. Health Aff. 33, 1975-1984 (2014). 
36. Commonwealth Fund. Addressing the Social Determinants of Health Through Medicaid Managed Care http://www.commonwealthfund.org/ /media/files/ publications/issue-brief/2017/nov/machledt_social_determinants_medicaid_ managed_care_ib_v2.pdf (2017). Accessed 29 Jan 2018.

37. Gottlieb, L. M., Garcia, K., Wing, H. \& Manchanda, R. Clinical interventions addressing nonmedical health determinants in Medicaid managed care. Am. J. Manag. Care 22, 370-376 (2016).

38. Centers for Medicare \& Medicaid Services. Health Homes https://www.medicaid. gov/medicaid/ltss/health-homes/index.html (2017). Accessed 25 Nov 2017.

39. Alley, D. E., Asomugha, C. N., Conway, P. H. \& Sanghavi, D. M. Accountable health communities--addressing social needs through medicare and medicaid. N. Engl. J. Med. 374, 8-11 (2016).

40. Vermont. Vermont Blueprint for Health: 2016 Annual Report. http:// blueprintforhealth.vermont.gov/sites/bfh/files/Vermont\%20Blueprint $\% 20$ for\% 20Health\%202016\%20Annual\%20Report.pdf (2016). Accessed 12 Jan 2018.

41. Conroy, K., Sandel, M. \& Zuckerman, B. Poverty grown up: how childhood socioeconomic status impacts adult health. J. Dev. Behav. Pediatr. 31, 154-160 (2010).

42. Halfon, N. \& Hochstein, M. Life course health development: an integrated framework for developing health, policy, and research. Milbank Q 80, 433-479 (2002). iii.

43. Vickery, K. D. et al. Cross-sector service use among high health care utilizers in Minnesota after medicaid expansion. Health Aff. 37, 62-69 (2018).

44. Gottlieb, L., Sandel, M. \& Adler, N. E. Collecting and applying data on social determinants of health in health care settings. JAMA Intern. Med. 173, 1017-1020 (2013).

45. Gottlieb, L. M., Wing, H. \& Adler, N. E. A systematic review of interventions on patients' social and economic needs. Am. J. Prev. Med. 53, 719-729 (2017).

46. Evidence Library. Social Interventions Research \& Evaluation Network https:// sirenetwork.ucsf.edu/tools/evidence-library (2017). Accessed 3 Nov 2017.

47. Guyatt, G. H. et al. GRADE: an emerging consensus on rating quality of evidence and strength of recommendations. BMJ 336, 924-926 (2008).

48. Garg, A. et al. Improving the management of family psychosocial problems at low-income children's well-child care visits: the WE CARE Project. Pediatrics 120, 547-558 (2007).

49. Garg, A., Toy, S., Tripodis, Y., Silverstein, M. \& Freeman, E. Addressing social determinants of health at well child care visits: a cluster RCT. Pediatrics 135, e296-e304 (2015).

50. Sege, R. et al. Medical-legal strategies to improve infant health care: a randomized trial. Pediatrics 136, 97-106 (2015).

51. Gottlieb, L. M. et al. Effects of social needs screening and in-person service navigation on child health: a randomized clinical trial. JAMA Pediatr. 170, e162521 (2016).

52. Krieger, J. W., Takaro, T. K., Song, L. \& Weaver, M. The Seattle-King County Healthy Homes Project: a randomized, controlled trial of a community health worker intervention to decrease exposure to indoor asthma triggers. Am. J. Public Health 95, 652-659 (2005).

53. Campbell, J. D. et al. Community health worker home visits for medicaidenrolled children with asthma: effects on asthma outcomes and costs. Am. J. Public Health 105, 2366-2372 (2015).

54. Williams, S. G. et al. Does a multifaceted environmental intervention alter the impact of asthma on inner-city children? J. Natl Med. Assoc. 98, 249-260 (2006).

55. Silverstein, $M$. et al. Effect of a clinic-based referral system to head start: a randomized controlled trial. JAMA 292, 968-971 (2004).

56. Mendelsohn, A. L. et al. Primary care strategies for promoting parent-child interactions and school readiness in at-risk families: the Bellevue Project for Early Language, Literacy, and Education Success. Arch. Pediatr. Adolesc. Med. 165, 33-41 (2011).

57. Dubowitz, H., Feigelman, S., Lane, W. \& Kim, J. Pediatric primary care to help prevent child maltreatment: the safe environment for every kid (SEEK) model. Pediatrics 123, 858-864 (2009).

58. Dubowitz, H., Lane, W. G., Semiatin, J. N. \& Magder, L. S. The SEEK model of pediatric primary care: can child maltreatment be prevented in a low-risk population? Acad. Pediatr. 12, 259-268 (2012).

59. Dubowitz, H. et al. The safe environment for every kid model: impact on pediatric primary care professionals. Pediatrics 127, e962-e970 (2011).

60. Feigelman, S., Dubowitz, H., Lane, W., Grube, L. \& Kim, J. Training pediatric residents in a primary care clinic to help address psychosocial problems and prevent child maltreatment. Acad. Pediatr. 11, 474-480 (2011).

61. Fleegler, E. W., Lieu, T. A., Wise, P. H. \& Muret-Wagstaff, S. Families' health-related social problems and missed referral opportunities. Pediatrics 119, e1332-e1341 (2007).

62. Beck, A. F. et al. Forging a pediatric primary care-community partnership to support food-insecure families. Pediatrics 134, e564-e571 (2014).

63. Fox, C. K., Cairns, N., Sunni, M., Turnberg, G. L. \& Gross, A. C. Addressing food insecurity in a pediatric weight management clinic: a pilot intervention. J. Pediatr. Health Care 30, e11-e15 (2016).
64. Sanders, L. M, Gershon, T. D, Huffman, L. C. \& Mendoza, F. S. Prescribing books for immigrant children: a pilot study to promote emergent literacy am ong the children of Hispanic immigrants. Arch. Pediatr. Adolesc. Med. 154, 771-777 (2000).

65. Bailey, R. \& Rhee, K. B. Reach out and read: promoting pediatric literacy guidance through a transdisciplinary team. J. Health Care Poor Under. 16, 225-230 (2005).

66. Silverstein, M., Iverson, L. \& Lozano, P. An English-language clinic-based literacy program is effective for a multilingual population. Pediatrics 109, E76-E76 (2002).

67. Needlman, R., Toker, K. H., Dreyer, B. P., Klass, P. \& Mendelsohn, A. L. Effectiveness of a primary care intervention to support reading aloud: a multicenter evaluation. Ambul. Pediatr. 5, 209-215 (2005).

68. Mendelsohn, A. L. et al. The impact of a clinic-based literacy intervention on language development in inner-city preschool children. Pediatrics 107, 130-134 (2001).

69. Beck, A. F. et al. Identifying and treating a substandard housing cluster using a medical-legal partnership. Pediatrics 130, 831-838 (2012).

70. Klein, M. D. et al. Doctors and lawyers collaborating to HeLP children--outcomes from a successful partnership between professions. J. Health Care Poor Under. 24, 1063-1073 (2013).

71. O'Toole, J. K., Burkhardt, M. C., Solan, L. G., Vaughn, L. \& Klein, M. D. Resident confidence addressing social history: is it influenced by availability of social and legal resources? Clin. Pediatr. 51, 625-631 (2012).

72. Pettignano, R., Caley, S. B. \& Bliss, L. R. Medical-legal partnership: impact on patients with sickle cell disease. Pediatrics 128, e1482-e1488 (2011).

73. Pettignano, R., Caley, S. B. \& McLaren, S. The health law partnership: adding a lawyer to the health care team reduces system costs and improves provider satisfaction. J. Public Health Manag Pract. 18, E1-E3 (2012).

74. Garg, A., Marino, M., Vikani, A. R. \& Solomon, B. S. Addressing families' unmet social needs within pediatric primary care: the health leads model. Clin. Pediatr. 51, 1191-1193 (2012).

75. Garg, A., Sarkar, S., Marino, M., Onie, R. \& Solomon, B. S. Linking urban families to community resources in the context of pediatric primary care. Patient Educ. Couns. 79, 251-254 (2010).

76. Weintraub, D. et al. Pilot study of medical-legal partnership to address social and legal needs of patients. J. Health Care Poor Under. 21, 157-168 (2010).

77. Becker, M. G., Hall, J. S., Ursic, C. M., Jain, S. \& Calhoun, D. Caught in the crossfire: the effects of a peer-based intervention program for violently injured youth. $J$. Adolesc. Health 34, 177-183 (2004).

78. Dicker, R. A. et al. Where do we go from here? Interim analysis to forge ahead in violence prevention. J. Trauma 67, 1169-1175 (2009).

79. Smith, R., Dobbins, S., Evans, A., Balhotra, K. \& Dicker, R. A. Hospital-based violence intervention: risk reduction resources that are essential for success. $J$. Trauma Acute Care Surg. 74, 976-980 (2013). discussion80-2.

80. Hassan, A. et al. Improving social determinants of health: effectiveness of a webbased intervention. Am. J. Prev. Med. 49, 822-831 (2015).

81. Nguyen, A. L. et al. A clinic-based pilot intervention to enhance diabetes management for elderly Hispanic patients. J. Health Environ. Educ. 8, 1-6 (2016).

82. Juillard, C. et al. A decade of hospital-based violence intervention: Benefits and shortcomings. J. Trauma Acute Care Surg. 81, 1156-1161 (2016).

83. Bottino, C. J., Rhodes, E. T., Kreatsoulas, C., Cox, J. E. \& Fleegler, E. W. Food insecurity screening in pediatric primary care: can offering referrals help identify families in need? Acad. Pediatr. 17, 497-503 (2017).

84. Garg, A., Boynton-Jarrett, R. \& Dworkin, P. H. Avoiding the unintended consequences of screening for social determinants of health. JAMA 316, 813-814 (2016).

85. Garg, A., Sheldrick, R. C. \& Dworkin, P. H. The inherent fallibility of validated screening tools for social determinants of health. Acad. Pediatr. 18, 123-124 (2017).

86. Haas, J. S. et al. Proactive tobacco cessation outreach to smokers of low socioeconomic status: a randomized clinical trial. JAMA Intern. Med. 175, 218-226 (2015).

87. Wooldridge, J. M. Introductory Econometrics: A Modern Approach 5th edn. (SouthWestern Cengage Learning, Mason, $\mathrm{OH}, 2013)$.

88. Berkowitz, S. A., Seligman, H. K., Rigdon, J., Meigs, J. B. \& Basu, S. Supplemental nutrition assistance program (SNAP) participation and health care expenditures among low-income adults. JAMA Intern. Med. 177, 1642-1649 (2017).

89. Berkowitz, S. A., Basu, S., Meigs, J. B. \& Seligman, H. K. Food insecurity and health care expenditures in the United States 2011-2013. Health Serv. Res. (2017); https://doi.org/10.1111/1475-6773.12730 (e-pub ahead of print 13 June 2017).

90. Hager, E. R. et al. Development and validity of a 2-item screen to identify families at risk for food insecurity. Pediatrics 126, e26-e32 (2010). 
91. Cutts, D. B. et al. US housing insecurity and the health of very young children. Am. J. Public Health 101, 1508-1514 (2011).

92. Gottlieb, L., Hessler, D., Long, D., Amaya, A. \& Adler, N. A randomized trial on screening for social determinants of health: the iScreen study. Pediatrics 134, e1611-e1618 (2014).

93. Chung, E. K. et al. Screening for social determinants of health among children and families living in poverty: a guide for clinicians. Curr. Probl. Pediatr. Adolesc. Health Care 46, 135-153 (2016).

94. Fierman, A. H. et al. Redesigning health care practices to address childhood poverty. Acad. Pediatr. 16, S136-S146 (2016).

95. Henize, A. W., Beck, A. F., Klein, M. D., Adams, M. \& Kahn, R. S. A road map to address the social determinants of health through community collaboration. Pediatrics 136, e993-e1001 (2015).
96. Palakshappa, D. et al. Clinicians' perceptions of screening for food insecurity in suburban pediatric practice. Pediatrics 140, e20170319 (2017).

97. Palakshappa, D. et al. Suburban families' experience with food insecurity screening in primary care practices. Pediatrics 140, e20170320 (2017).

98. Cheng, T. L., Emmanuel, M. A., Levy, D. J. \& Jenkins, R. R. Child health disparities: what can a clinician do? Pediatrics 136, 961-968 (2015).

99. Colvin, J. D., Bettenhausen, J. L., Anderson-Carpenter, K. D., Collie-Akers, V. \& Chung, P. J. Caregiver opinion of in-hospital screening for unmet social needs by pediatric residents. Acad. Pediatr. 16, 161-167 (2016).

100. SIREN. Introducing the Social Interventions Research and Evaluation Network https://sirenetwork.ucsf.edu/tools-resources/resources/introducing-socialinterventions-research-and-evaluation-network (2017). Accessed 7 Nov 2017. 